\title{
Demonstrações Matemáticas Dinâmicas
}

\author{
Dynamic Math Demonstrations
}

Jorge Cássio Costa Nóbriga*

Universidade Federal de Santa Catarina - UFSC

\begin{abstract}
Resumo
Neste artigo, é apresentado um conceito que foi denominado de Demonstrações Matemáticas Dinâmicas. Para justificar a necessidade da criação de tal conceito e poder fundamentá-lo, foi necessário fazer adaptações em alguns conceitos da Teoria dos Registros de Representações Semióticas. Conceitos como Tratamento e Conversão foram adaptados para Tratamento Dinâmico e Conversão Dinâmica. De antemão, é importante destacar que não se trata de uma nova forma de demonstração, mas sim de como apresentá-la. Trata-se de um tipo de demonstração feita em ambientes de Geometria Dinâmica e que tem o propósito de explicar e não apenas de validar. A criação do conceito era necessária porque as demonstrações dinâmicas têm características próprias que as diferem das demonstrações convencionais. As Demonstrações Matemáticas Dinâmicas foram essenciais para a produção de um livro dinâmico de matemática. Embora não se tenha feito ainda uma análise sistemática a respeito das contribuições da Demonstração Dinâmica para o processo de ensino e aprendizagem, os primeiros experimentos indicam que o uso desse tipo demonstração pode auxiliar a compreensão, desenvolver a aprendizagem com autonomia e potencializar o poder argumentativo dos estudantes.
\end{abstract}

Palavras-chave: GeoGebra. Demonstração Matemática. Representações Semióticas. Demonstração Matemática Dinâmica.

\begin{abstract}
In this article, we present a concept that was called Dynamic Mathematical Demonstrations. In order to justify the need to create such a concept and to be able to substantiate it, it was necessary to make adaptations in some concepts of the Theory of Registers of Semiotic Representations. Concepts such as Treatment and Conversion have been adapted for Dynamic Treatment and Dynamic Conversion. In advance, it is important to point out that this is not a new form of demonstration, but rather how to present it. It is a kind of demonstration wich is meant to explain and not just to validate. The creation of the concept was necessary because the dynamic demonstrations have their own characteristics that differ them from the conventional demonstrations. The Dynamic Mathematical Demonstrations were essential for the production of a dynamic mathematical book. Although a systematic analysis of the contributions of Dynamic Demonstrations to the teaching and learning process has not yet been made, early experiments indicate that the use of this kind of demonstration may help understanding, develop learning with autonomy and to increase the students' argumentative power.
\end{abstract}

Keywords: GeoGebra. Mathematical Demonstration. Semiotic Representations. Dynamic Mathematical Demonstration.

\footnotetext{
* Doutor em Educação pela Universidade de Brasília (UnB). Professor da Universidade Federal de Santa Catarina (UFSC), Blumenau, SC, Brasil. E-mail: j.cassio@ufsc.br
} 


\section{Introdução}

Em primeiro lugar, é preciso ficar claro que este texto não trata da Demonstração Matemática no sentido de compreensão do funcionamento do discurso matemático. O foco é na demonstração como um elemento essencial para compreensão das justificativas das propriedades dos objetos matemáticos. De maneira geral, a evidência da compreensão em matemática é verificada pela capacidade de resolver exercícios (ou problemas) usando as propriedades matemáticas. Aqui considera-se que a evidência da compreensão está mais relacionada às justificativas das propriedades. Por outro lado, não se compactua com uma concepção excessivamente rigorosa e formal da matemática. Até porque o excesso de rigor e formalismos pode dificultar a compreensão da demonstração. Além disso, Gravina (2015) diz que entender o sentido de uma teoria axiomatizada, do significado e da necessidade de uma demonstração, ser autor de demonstrações não é nada simples e espontâneo. Nesse sentido é que se propõe uma forma diferenciada de apresentar as demonstrações.

Para poder entender melhor o conceito, será feita, primeiramente, uma breve revisão a respeito dos Registros de Representações Semióticas, porque o conceito proposto se fundamenta nessa teoria. Em seguida, são apresentadas algumas adaptações dos conceitos dessa teoria para o contexto da Geometria Dinâmica (GD). Depois é abordado o conceito de Demonstração Matemática nos ambientes tradicionais e nos computadores. Por fim, é apresentado o conceito, as características e um exemplo de Demonstração Matemática Dinâmica.

\section{Teoria dos Registros de Representações Semióticas de Duval}

Poder-se-ia dizer que um primeiro "postulado" da teoria proposta por Duval é de que não se pode ter compreensão em matemática se não se distingue um objeto de sua representação (Duval, 2009). De acordo com ele, a noção de representação pode ser vista como a forma de uma informação ser constituída, como uma "codificação da informação". Em relação as Representações Semióticas, ele diz o seguinte:

[...] A especificidade das representações semióticas consiste em serem relativas a um sistema particular de signos, a linguagem, a escritura algébrica ou os gráficos cartesianos, e em poderem ser convertidas em representações "equivalentes" em outro sistema semiótico, mas podendo tomar significações diferentes para o sujeito que as utiliza. A noção de representação semiótica pressupõe, então, a consideração de sistemas semióticos diferentes e de uma operação cognitiva de conversão das representações de um sistema semiótico para um outro. Essa operação tem sido 
primeiramente descrita como uma "mudança de forma" (Duval, 2009, p. 32).

Para exemplificar, podem-se considerar três formas de representar o objeto "Teorema de Pitágoras" que são apresentadas em livros didáticos:

- Representação por meio da linguagem natural (língua materna): Em todo triângulo retângulo, o quadrado da medida da hipotenusa é igual à soma dos quadrados das medidas dos catetos.

- Representação por meio de símbolos: $a^{2}=b^{2}+c^{2}$ (em que "a", "b" e "c" são as medidas dos lados de um triângulo retângulo)

- Representação por meio de uma figura:

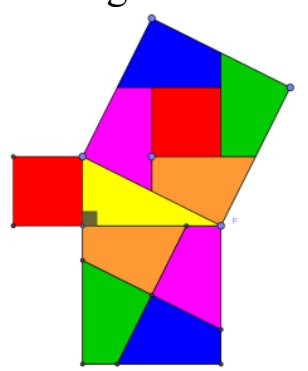

Duval (2009) diz que é importante que o uso da pluralidade potencial das diversas formas de representações semióticas não seja confundido com o objeto em questão, ou seja, não se pode dizer que apenas umas das representações anteriores é o "Teorema de Pitágoras". A distinção entre objeto e sua representação é difícil e gera um problema comum no processo de aprendizagem e ensino da matemática. O mesmo autor afirma que "toda confusão entre o objeto e sua representação provoca, com o decorrer do tempo, uma perda de compreensão" (Duval, 2009, p. 14). Para que haja compreensão do conceito é necessário que o estudante conheça as diferentes representações, as relações entre elas, suas condições de existência e saiba aplicar tal conhecimento em outros contextos. Para isso, o autor diz que fazer uso de diversas formas de representar um mesmo objeto, além da língua materna ou das imagens, tais como tabelas, gráficos, símbolos, diagramas, escritas algébricas, esquemas, são atividades cognitivas necessárias para a aprendizagem em matemática. Os registros de representação que compõem o Sistema Semiótico da Matemática podem ser divididos em de Cunho Discursivo (Registro de Representação Linguística e Registro de Representação Simbólica) e Cunho não discursivo (Registro de Representação Visual)

Duval (2009) afirma que existem 3 atividades cognitivas inerentes à semiósis: formação e transformação (tratamento e conversão). A formação de representações é a primeira atividade. Trata-se de uma forma de exprimir uma representação mental ou evocar um objeto real. Essa formação implica na seleção do conjunto de caracteres e determinações 
de um conteúdo percebido, imaginado ou já representado em função de possibilidades de representação próprias ao registro escolhido. O mesmo autor diferencia as transformações que ocorrem dentro de um mesmo registro das transformações que ocorrem de um registro para o outro. De acordo com ele, o tratamento é uma transformação que se efetua dentro de um mesmo registro. Por exemplo, ao desenvolver a expressão $(x+2)^{2}$ de forma que fique $x^{2}+$ $4 x+4$ tem-se um exemplo da função de tratamento no registro simbólico (algébrico). A conversão é uma transformação que se efetua ao passar de um registro a outro. Por exemplo, o teorema "Em todo triângulo as medida dos lados são proporcionais aos senos dos ângulos opostos" pode ser escrito através da equação $\frac{a}{\operatorname{sen}(A)}=\frac{b}{\operatorname{sen}(B)}=\frac{c}{\operatorname{sen}(C)}$ (onde a, b e c, representam as medidas dos lados do triângulo e A, B e C representam as medidas dos ângulos internos do triângulo). Nesse caso, há uma conversão do registro de representação linguística para o registro de representação simbólica.

Duval (2009, p. 101) diz que é importante “[...] possibilitar a exploração de todas as variações possíveis de uma representação num registro fazendo prever, ou observar, as variações concomitantes da representação em outro registro". Diante disso, cabem os seguintes questionamentos: Como possibilitar isso? Quais instrumentos possibilitam uma exploração que permita prever ou observar as variações concomitantes de representação em outro registro? A palavra "concomitante" significa ao mesmo tempo ou simultaneamente. É possível perceber tais variações em registros feitos em ambientes estáticos (por exemplo, caderno ou quadro)? Essas perguntas motivam a pensar na relação do uso do computador com as representações semióticas. Isso será visto no tópico seguinte.

\subsection{Formação, Tratamento e Conversão em Softwares de Geometria Dinâmica}

Em relação às contribuições do computador sobre os modos de representações semióticas, Duval (2011) diz que tal ferramenta não constitui um novo registro de representação, porque as representações que eles exibem são as mesmas que aquelas produzidas graficamente no papel para uma apreensão visual. Para interpretar os gráficos em um monitor, é necessário que se seja capaz de reconhecer os valores visuais matematicamente pertinentes e coordená-los com os termos das representações correspondentes. De fato, os softwares não constituem outro registro de representação. O que eles fazem é possibilitar novas formas de explicitar as representações e suas transformações. Ou seja, os computadores constituem um novo modo de produção de representações, sobretudo, para as atividades 
cognitivas de formação, tratamento e conversão. Isso fica bastante evidente nos softwares de Geometria Dinâmica (GD).

Bellemain e Correia (2004) definem a Geometria Dinâmica ${ }^{1}$ como sendo o estudo das propriedades dos conjuntos de desenhos representando uma mesma figura ou respeitando um mesmo conjunto de especificações. Já Isotani e Brandão (2006) dizem que a GD é a implementação computacional da "geometria tradicional", aquela de régua e compasso. Eles afirmam que o termo "dinâmico" do nome pode ser mais bem entendido como oposição à estrutura "estática" das construções da geometria tradicional. Com o auxílio de softwares de GD, é possível tornar manipuláveis as representações semióticas como se fossem objetos concretos. Podem-se fazer tais representações sem ter, necessariamente, "habilidades manuais”. Por exemplo, em softwares como o GeoGebra, o procedimento para fazer um círculo não é o mesmo do que o de fazer um desenho de um círculo no papel. Em geral, a produção no papel, como o desenho de um círculo, é uma simples reprodução de uma figura já vista. Em softwares de GD, constrói-se a partir das propriedades da figura, ou seja, constrói-se o círculo a partir de um ponto (centro) e raio, constrói-se a partir de três pontos não alinhados etc. Pode-se também manipular as representações de diferentes maneiras, de forma contínua e o mais interessante: fazer de forma simultânea diferentes representações de um mesmo objeto. Esse aspecto dinâmico é apenas uma consequência da potência ilimitada do tratamento que permite desempenhar uma função que nenhum dos outros modos fenomenológicos permite: a função de simulação que possibilita a exploração heurística de objetos matemáticos (Duval, 2011).

O termo Dinâmico tem a ver com algo que se modifica de maneira contínua. No contexto dos softwares de GD o conceito está relacionado com o princípio de manipulação direta. De acordo com Bellemain (2001) tal princípio permite ao usuário a sensação de agir direta e livremente sobre a representação do objeto e controlar imediatamente os efeitos dessa ação. Com o auxílio do mouse, pode-se arrastar ou manipular diferentes representações e visualizar os efeitos de suas ações. Isso contribui para a percepção das relações entre as representações, formulação de conjecturas, identificação de contraexemplos etc.

Pode-se perceber que, quando produzidas em ambientes de GD, as atividades cognitivas formação, tratamento e conversão têm características diferentes das produzidas em

\footnotetext{
${ }^{1}$ Recentemente o conceito de Geometria Dinâmica foi ampliado para Matemática Dinâmica (MD) que seria uma extensão da definição de "Geometria Dinâmica" (Preiner, 2008). Os softwares de GD também são chamados de Ambientes de Geometria Dinâmica (AGD). Este trabalho não faz distinção entre a GD, AGD e a MD. Assim, daqui para frente será considerada apenas a GD.
} 
ambientes tradicionais (estáticos). Nesse sentido, Salazar e Almouloud (2015) apresentam os conceitos Formação Dinâmica, Registro Figural Dinâmico e Tratamento Dinâmico. Para esses autores

A formação de uma representação semiótica em AGD, que chamamos formação dinâmica, se dá quando o sujeito, para representar um objeto geométrico, escolhe uma ferramenta (da barra de ferramentas) que lhe permita criar a figura desejada. Nessa ação, o sujeito deve mobilizar conhecimentos de geometria (Salazar \& Almouloud, 2015, p.928).

Tais autores restringem a formação dos Registros de Representação Visual, especificamente a representação geométrica do objeto. Para Salazar (2011) o Registro Figural Dinâmico é um registro figural feito em ambientes de Geometria Dinâmica. Por outro lado, é necessário ter o cuidado para não achar que todo desenho feito nos ambientes de GD são registros figurais dinâmicos. O GeoGebra possui ferramentas que permitem a criação de registros figurais (círculos, cônicas, polígonos, etc) a partir de propriedades, mas ele também possui a ferramenta "caneta" que permite a criação de simples desenhos na janela de visualização. Duval (2011) diz que o desenho é a configuração particular que mostra no papel, no quadro negro ou no monitor do computador, enquanto a figura seria as propriedades do objeto representado pelo desenho ou, ainda, a classe de todos os desenhos que podem ser representações visuais desse objeto. Gravina (2015) diz que uma figura dinâmica é entendida como uma coleção de "desenhos em movimento", que respeita certo procedimento de construção. Na figura 1-a temos um Registro Figural Dinâmico, porque permite arrastar os vértices e manter as propriedades do triângulo equilátero. Já a figura 1-b é um simples desenho que não permite manipulações.

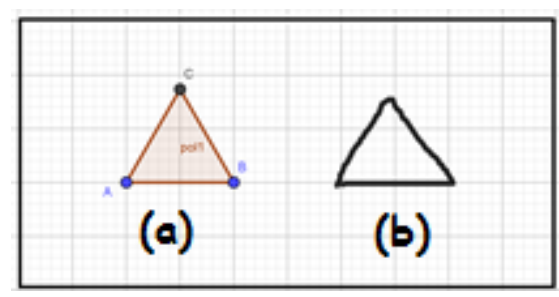

Figura 1- Figura e Desenho feitos no GeoGebra

O conceito Registro Figural Dinâmico proposto por Salazar (2011) pode ser ampliado para Registro Visual Dinâmico, porque assim ele incluiria também as representações gráficas e icônicas.

Assim como o Registro Visual tem características específicas nos ambientes de GD, as atividades cognitivas de formação dos Registros Linguísticos e Simbólicos também podem ter. Dessa forma, eles também precisam de conceitos apropriados. Um Registro Simbólico 
Dinâmico é um registro em que, quando se alteram certos parâmetros, toda representação é alterada dinamicamente. A figura 2 apresenta um exemplo em que é possível ver o processo de resolução de uma equação de $2^{\circ}$ grau. $\mathrm{O}$ usuário pode alterar os seletores que representam os coeficientes a, b e c da equação. Quando ele faz isso, todo o cálculo e resultados se ajustam. Na figura 2 é possível ver o caso em que $a=1, b=2$ e $c=-3$ e também o caso em $a=-$ $1, b=2$ e $c=3$.

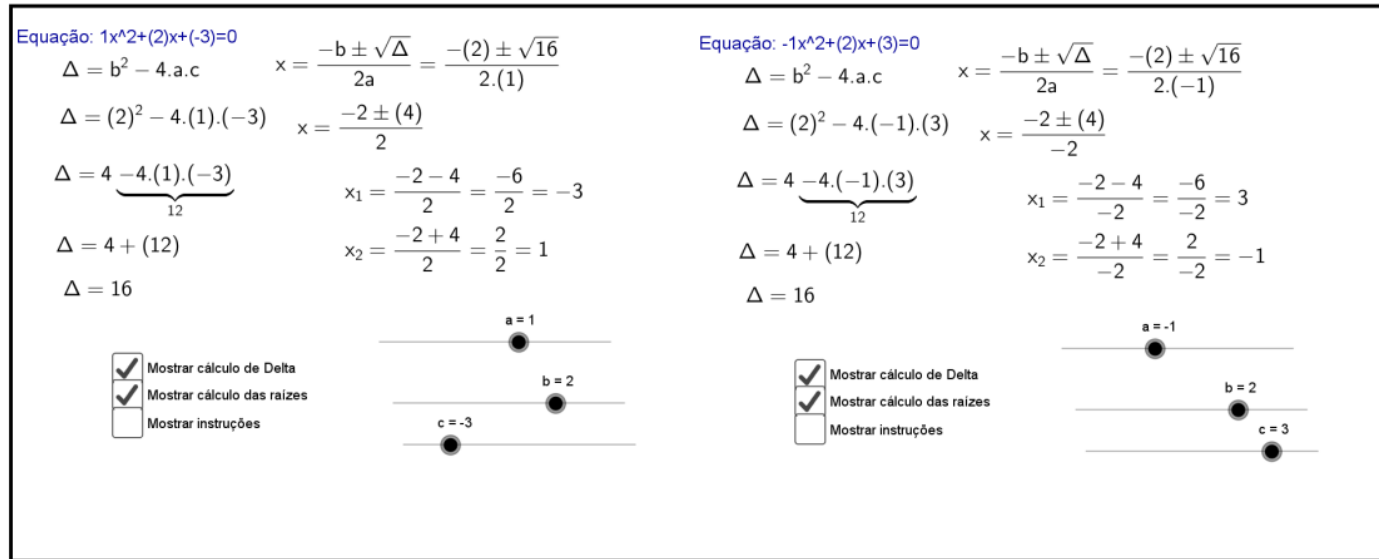

Figura 2- Exemplo de Registro Simbólico Dinâmico ${ }^{2}$

(Disponível em https://ggbm.at/HdbcVCr8 acesso 23 de abril de 2018)

Um Registro Linguístico Dinâmico é um registro em que o texto é alterado dinamicamente quando ele está associado a alguma característica de outra representação e ela sofre alguma modificação que altera alguma propriedade. A figura 3 apresenta um exemplo.

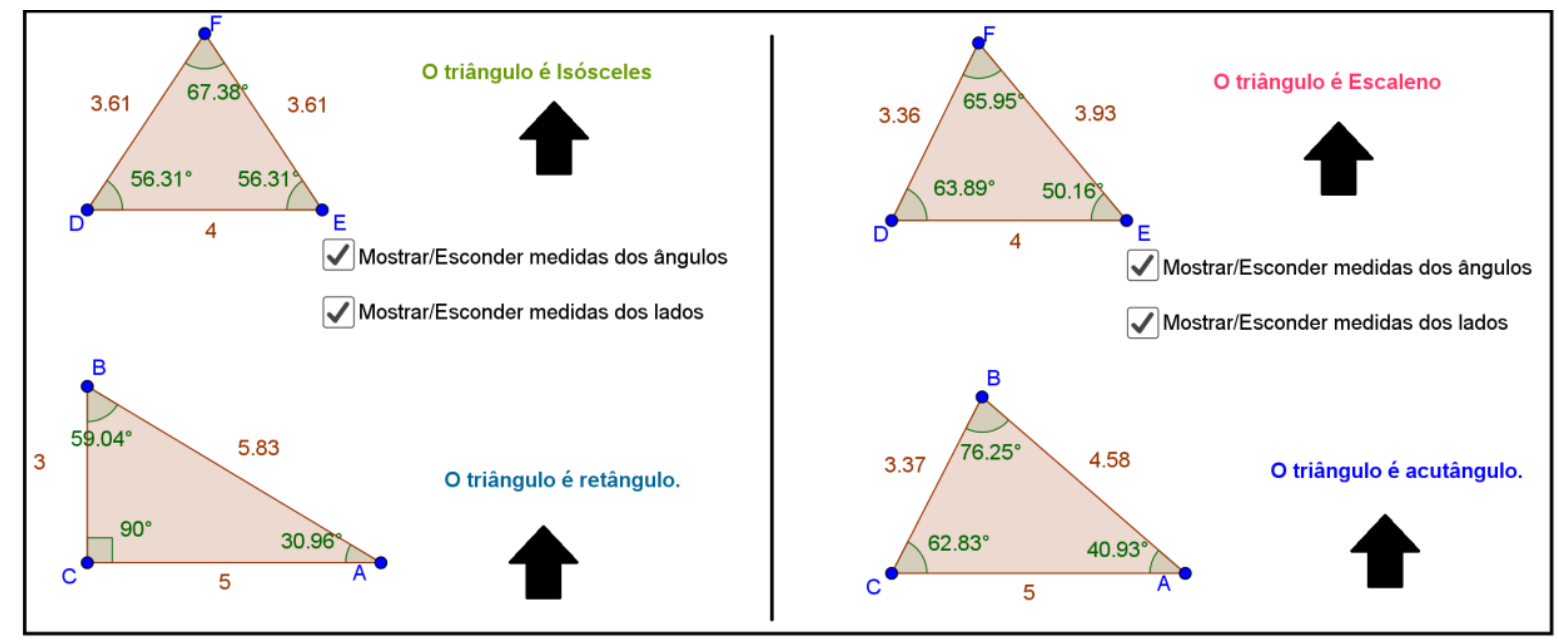

Figura 3- Exemplo de Registro Linguístico Dinâmico

(Disponível em https://ggbm.at/MSYKSD6w acesso em 23 de abril de 2018)

\footnotetext{
${ }^{2}$ Para a compreensão das ideias apresentadas neste artigo, é extremamente importante que o leitor abra os links apresentados no texto.
} 
Na figura 3 há uma construção em que é possível alterar a posição dos vértices dos triângulos e ver os textos com as classificações. Os textos se alteram, dinamicamente, adequando-se ao tipo de classificação de cada triângulo.

Quando se mescla, dinamicamente, Registros Linguísticos e Simbólicos têm-se os Registros Discursivos Dinâmicos, ou seja, textos que mesclam palavras, números e símbolos matemáticos que podem ser alterados pelo usuário. Um exemplo é apresentado na figura 4.

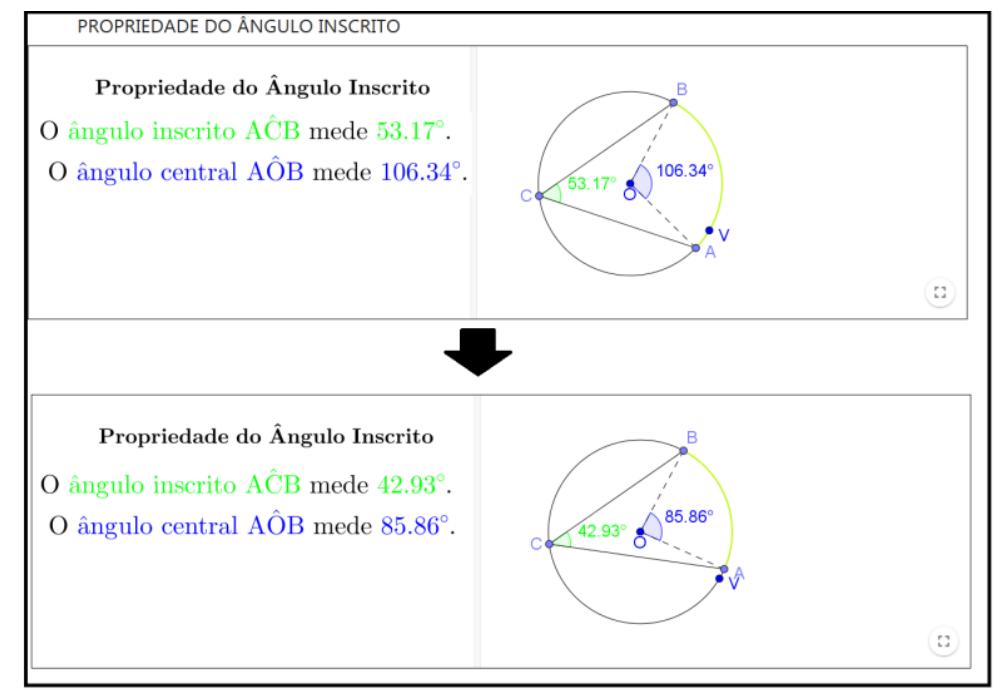

Figura 4- Registros Discursivos Dinâmicos

(Disponível em https://ggbm.at/PybdQ59b acesso em 23 de abril de 2018)

$\mathrm{Na}$ figura 4, há uma construção em que é possível alterar a posição dos pontos A, B ou $\mathrm{C}$ e observar as medidas dos ângulos central e inscrito. O Registro Discursivo do lado esquerdo é modificado quando as medidas dos ângulos são alteradas no Registro Visual Dinâmico.

Como se pode perceber nos exemplos, para que haja a percepção do caráter dinâmico é preciso fazer movimentos nas representações. Salazar \& Almouloud (2015, p.930) apresentam o conceito de Tratamentos Dinâmicos restritos aos Registros Figurais:

...os tipos de tratamentos de uma figura que identificamos neste estudo quando se utiliza AGD são mudar a posição da figura sem modificá-la (para isso, se utiliza a função de manipulação direta), mudar o comprimento dos lados da figura (aqui, se utiliza a função de arrastamento e também se pode utilizar a ferramenta de homotetia) e reconfigurar a figura (neste caso, se utiliza a função de arrastamento e outras ferramentas especificas que dependem da figura construída) .

Tais autores alertam ainda que "esses tratamentos não se realizam necessariamente por separado ou de maneira sequencial, já que, no âmbito de um AGD, podem se realizar de maneira simultânea" (p.930). Todavia, pode-se discordar com esses autores quando eles dizem 
que mudar a posição de uma figura sem modificá-la caracteriza um Tratamento Dinâmico. De fato, pode não ser nem mesmo um Tratamento, pois apenas alterar a posição de uma figura pode não gerar mudanças significativas a ponto de "constituir uma relação de conhecimento em comparação as representações iniciais" (Duval, 2005 citado por Salazar e Almouloud, 2015, p. 921).

É necessária uma definição de Tratamento Dinâmico que contemple os Registros Linguístico, Figural e Simbólico. Nesse sentido, propõe-se que o Tratamento Dinâmico seja considerado como as transformações que ocorrem num mesmo registro e que sejam produzidas num ambiente que permita os princípios de manipulação direta, constituindo uma relação de conhecimento em comparação com as representações iniciais. Já a Conversão Dinâmica seria as transformações que ocorrem, simultaneamente, de um registro para outro e que sejam produzidas num ambiente que permita os princípios de manipulação direta, constituindo uma relação de conhecimento em comparação com as representações iniciais. Assim, diante dos conceitos apresentados, pode-se dizer que os Registros Linguísticos, Simbólicos e Visuais Dinâmicos são aqueles que permitem tratamentos e conversões dinâmicas. A figura 4 apresenta um exemplo em que há combinação de tratamentos e conversões dinâmicas para a percepção da propriedade do ângulo inscrito na circunferência.

\section{Demonstração Matemática}

A demonstração pode ser considerada como uma sequência de argumentos que seguem regras da lógica para mostrar que um enunciado é verdadeiro quando se assume certos axiomas, definições e teoremas já demonstrados. Bicudo (2002) diz que demonstrar uma proposição (exprimindo uma propriedade de um conceito) significa argumentar pela aceitação de sua validade, a partir da validade de outras proposições já demonstradas. A Demonstração Matemática é também chamada de Prova Matemática. O principal propósito de uma demonstração é a validação.

Hanna (1990) distingue a demonstração formal da demonstração aceitável, e estas da demonstração no contexto da matemática escolar:

Demonstração formal: a demonstração como conceito teórico da lógica formal (ou meta-lógica), que pode ser encarado como o ideal do qual a prática matemática apenas se aproxima. Demonstração aceitável: a demonstração como conceito normativo que define o que é aceitável para os matemáticos profissionais. O ensino da demonstração: a demonstração como uma atividade matemática escolar que serve para esclarecer ideias que vale a pena tornar conhecidas dos alunos. (p. 6)

Este texto não tem a intenção de aprofundar o debate sobre a distinção desses três 
tipos de demonstrações, porque interessa as distinções que dizem respeito aos propósitos das demonstrações: Demonstração que Prova e Demonstração que Explica. Hanna (1990) aborda o conceito de demonstração com propósito de explicação e defende que, sempre que possível, é preferível apresentar este tipo de demonstração aos alunos. Para essa autora a demonstração que prova e a demonstração que explica são ambas legítimas. A diferença básica é que uma demonstração que prova só mostra que um teorema é verdadeiro, enquanto uma demonstração que explica mostra também porque é que um teorema é verdadeiro. Uma demonstração que tenha apenas o propósito de validação pode não ter significado para o estudante. O significado passa pela experimentação, formulação de conjecturas, percepção de propriedades e justificativa. A título de exemplo são apresentadas duas demonstrações para o Teorema de Pitágoras.

\section{$1^{\mathrm{a}}$ - Demonstração dos Elementos de Euclides}

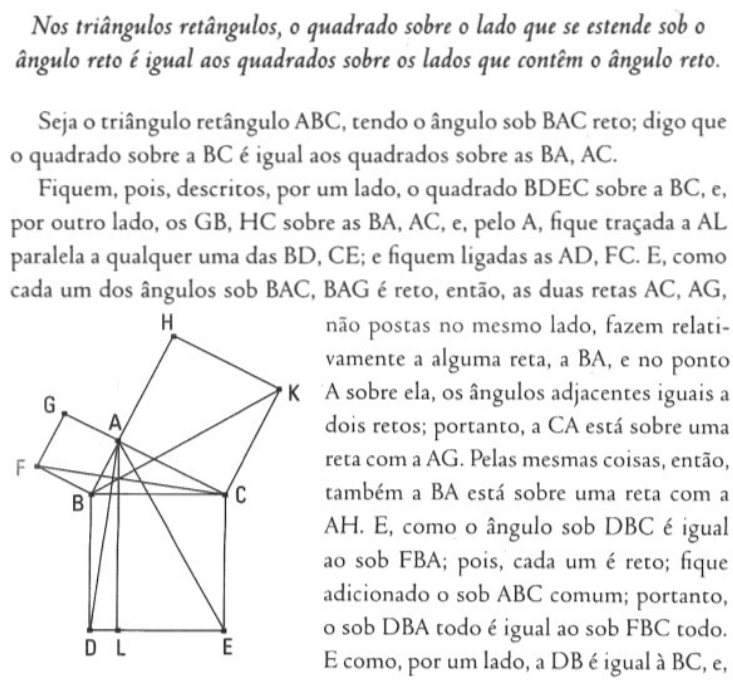

\begin{abstract}
por outro lado, a FB, à $\mathrm{BA}$, então, as duas $\mathrm{DB}, \mathrm{BA}$ são iguais às duas $\mathrm{FB}, \mathrm{BC}$ cada uma a cada uma; e o ângulo sob DBA é igual ao ângulo sob FBC; portanto, a base $\mathrm{AD}$ [é] igual à base $\mathrm{FC}$, e o triângulo $\mathrm{ABD}$ é igual ao triângulo FBC; e, por um lado, o paralelogramo BL [é] o dobro do triângulo ABD; pois, tanto têm a mesma base BD quanto estão nas mesmas paralelas BD, $\mathrm{AL}$; e, por outro lado, o quadrado GB é o dobro do triângulo $\mathrm{FBC}$; pois, de novo, tanto têm a mesma base FB quanto estão nas mesmas paralelas FB, GC. [Mas os dobros das coisas iguais são iguais entre si;] portanto, também o paralelogramo BL é igual ao quadrado GB. Do mesmo modo, então, sendo ligadas as $\mathrm{AE}, \mathrm{BK}$, será provado também o paralelogramo $\mathrm{CL}$ igual ao quadrado $\mathrm{HC}$; portanto, o quadrado BDEC todo é igual aos quadrados GB, HC. E, por um lado, o quadrado BDEC foi descrito sobre a BC, e, por outro lado, os GB, HC, sobre as BA, AC. Portanto, o quadrado sobre o lado BC é igual aos quadrados sobre os lados BA, AC.

Portanto, nos triângulos retângulos, o quadrado sobre o lado que se estende sob o ângulo reto é igual aos quadrados sobre os lados que contêm o [ângulo] reto; o que era preciso provar.
\end{abstract}

Figura 5- Proposição 47 do livro 1 dos Elementos de Euclides (Bicudo, 2009, p. 132)

A $1^{\mathrm{a}}$ demonstração (figura 5) tem mais características de uma Demonstração que Prova. Nota-se que há apenas o uso dos registros de representações linguístico e visual. Percebe-se tratamento apenas no registro de representação linguístico. A linguagem usada é voltada para alguém que já domina bem as técnicas e os critérios de validade. Não parece haver preocupação em explicar os porquês de cada afirmação. A validação é efetivada por meio das conexões lógicas entre as afirmações. Apesar de não se poder afirmar que um leigo (não matemático) não entenderia a demonstração, não se percebe elementos que mostrem a finalidade de explicar de maneira didática.

Vejamos a $2^{\mathrm{a}}$ demonstração, apresentada num livro didático de Ensino Médio: 


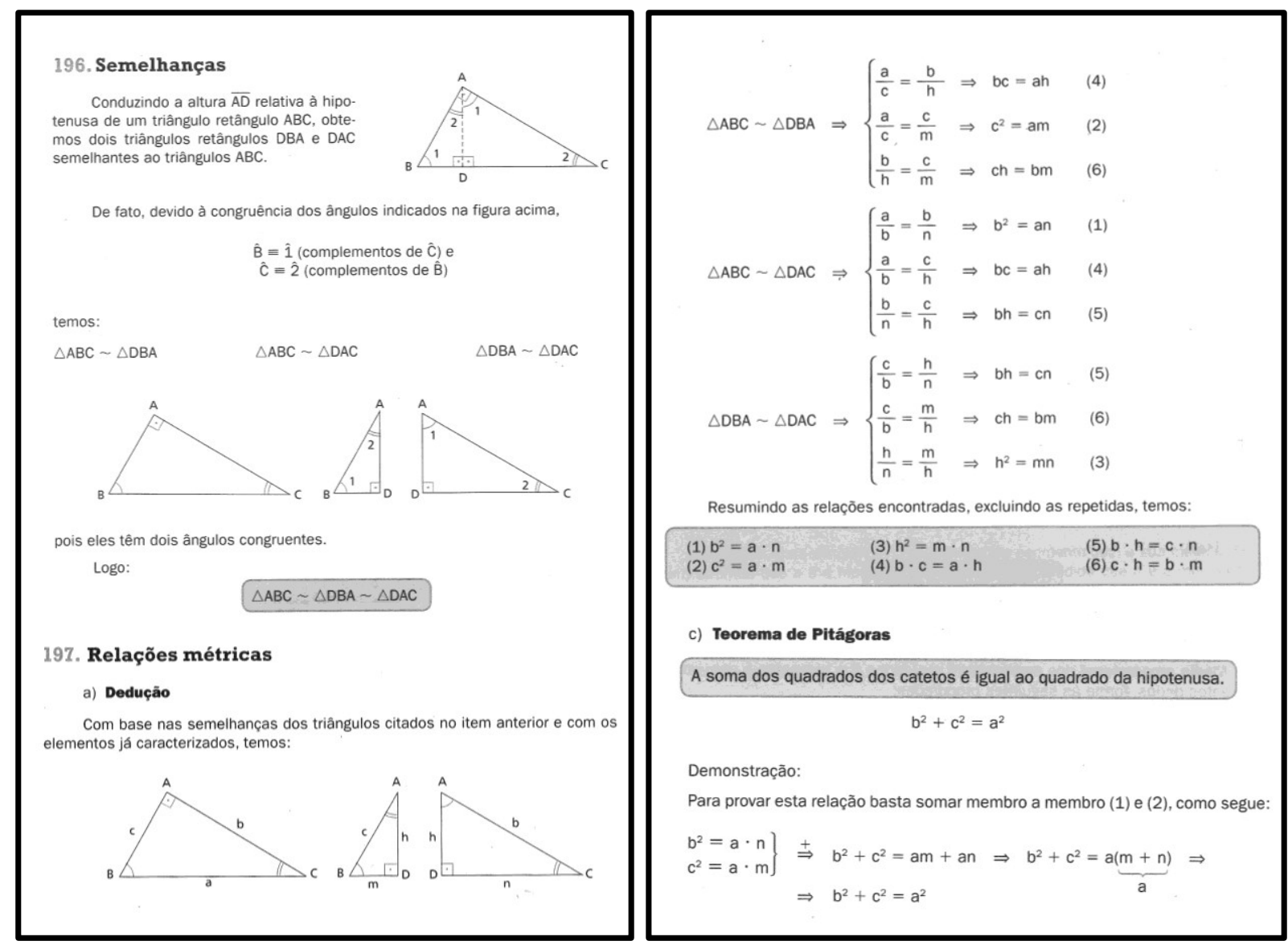

Figura 6-Demonstração do teorema de Pitágoras

(Dolce \& Pompeu, 2013.p.192)

A figura 6 apresenta uma Demonstração que Explica. Naturalmente, ela também prova. Diferentemente da anterior, esta demonstração utiliza os registros de representações linguístico, simbólico e visual. Além disso, são perceptíveis os tratamentos e conversões:

- Tratamento no registro de representação simbólico: $\frac{a}{c}=\frac{b}{h} \rightarrow b c=a h$

- Tratamento no registro de representação visual:

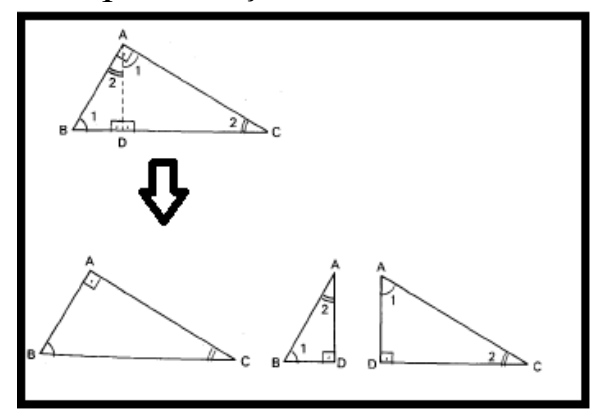

- Conversão do registro linguístico para o simbólico:

\begin{tabular}{|l|}
\hline \multicolumn{1}{|c|}{ A soma dos quadrados dos catetos é igual ao quadrado da hipo- } \\
tenusa. \\
$\qquad \mathrm{b}^{2}+\mathrm{c}^{2}=\mathrm{a}^{2}$
\end{tabular}


A demonstração explicita e faz uso de um teorema necessário para a compreensão: o teorema da Semelhança de Triângulos. Apresenta marcas de ângulo com características específicas para facilitar a identificação nas diferentes representações visuais. Enfim, são vários os elementos que evidenciam uma preocupação em explicar didaticamente. Todavia, uma questão que deve ser feita é: quais são os fatores que podem levar os estudantes a não entenderem a demonstração?

Duval (1998) diz que o discurso dedutivo característico da matemática e o discurso argumentativo utilizado na linguagem natural têm características cognitivas muito diferentes. Não basta dominar a linguagem natural para entender a demonstração. A leitura de uma demonstração matemática não é feita "linearmente", de cima para baixo, como nos casos dos textos "convencionais". Ela exige que se desloque, frequentemente, o olhar para as representações visual, linguística e simbólica. Uma ida e vinda contínua entre as representações. Como estabelecer uma ordem de leitura das demonstrações em que as representações aparecem todas de uma vez e em diferentes posições? Duval (2009) diz que é comum vermos em livros de matemáticas e outras áreas, diversas representações em uma mesma página: frases em língua natural, fórmulas, figuras geométricas, gráficos cartesianos etc. Como se atividade de conversão fosse algo natural.

No caso da demonstração contida na figura 6 não há a explicitação dos nomes dos elementos (projeções e alturas) associando com suas representações simbólicas e visuais. Também não explicita quais são os lados homólogos dos triângulos semelhantes, dificultando a compreensão das relações estabelecidas. Tais ausências são bastante comuns nos livros didáticos.

Gravina (2015, p. 240) destaca outra dificuldade relacionada à compreensão das demonstrações:

No processo de demonstração o tratamento a ser dado ao componente figural é sempre uma fonte de dificuldade; é preciso transformar o registro desenho, mantendo-o sempre sob o controle da argumentação, e de tal forma que possam ser construídos componentes figurais de teoremas e conceitos já sob domínio e que vão garantir o fluir da argumentação. Quão mais implícitos estão no componente figural os elementos geométricos necessários para concatenação lógico-inferencial de hipótese e tese do teorema, tão mais difícil se torna o processo de demonstração.

Diante das dificuldades levantadas, o que fazer para tentar superá-las e permitir que se possa compreender as demonstrações? Há muitas discussões acerca do uso do computador para a produção de demonstrações, como por exemplo, o Teorema das quatro cores. Também há quem defenda que os softwares instigam os estudantes, abrindo perspectivas de investigações e busca de resultados que são induzidos pelas construções dinâmicas (Lourenço, 
2002). O próximo tópico abordará isso.

\subsection{O uso do computador para demonstrações (ou "mostrações")}

Neste artigo, o debate sobre o uso do computador está restrito às novas formas de apresentar os teoremas e as demonstrações. Lourenço (2002), usando o software de GD Cabri-Géomètre, mostra uma maneira de apresentar a demonstração do Teorema de Pitágoras ${ }^{3}$ explorada nos Elementos de Euclides. Na figura 7, o quadrado formado com a hipotenusa é dividido em dois retângulos que deslizam e se encaixam perfeitamente nos outros quadrados formados pelos catetos.

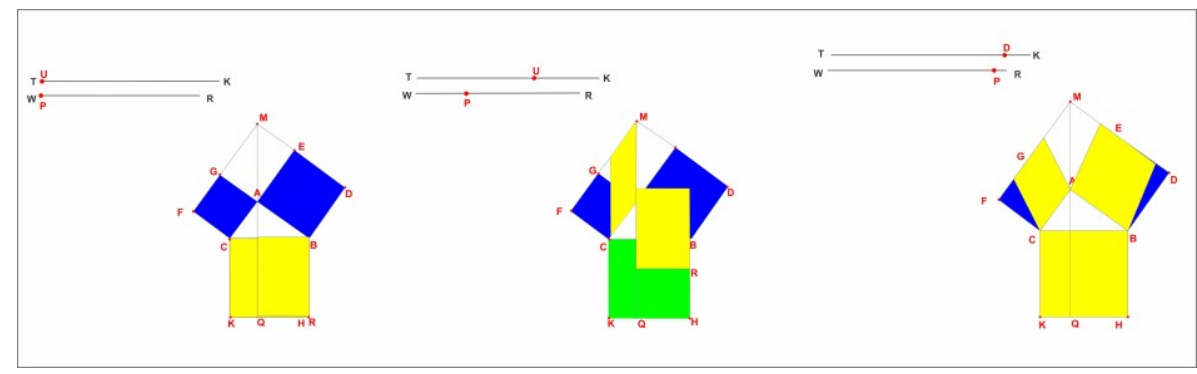

Figura 7-Demonstração do Teorema de Pitágoras feita no Cabri 2 (Lourenço, 2002)

Em relação a essa construção pode-se fazer alguns questionamentos: Os estudantes se convenceriam de fato de que os retângulos têm áreas iguais as dos quadrados formados pelos catetos? Não poderiam achar que foi um truque? E se se convencessem, será que teriam compreendido de fato? A partir da ideia de mostrar que tem áreas iguais, poderia ser feita a seguinte construção no GeoGebra (ou mesmo papel).

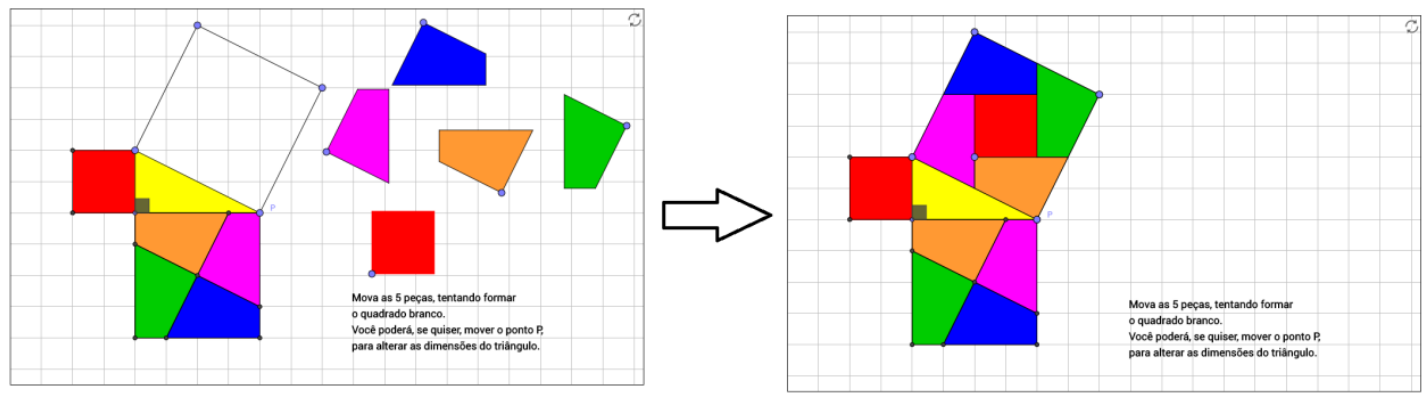

Figura 8-Construção para demonstração do Teorema de Pitágoras (Disponível em https://ggbm.at/WG6VtwBB acesso 24 de abril de 2018)

As construções anteriores têm o propósito de mostrar o teorema de Pitágoras a partir da equivalência de área. Mas de que forma, a partir da manipulação das construções, o estudante teria condições de fazer a conversão para o registro linguístico (Em todo triângulo,

\footnotetext{
${ }^{3}$ Uma construção semelhante pode ser vista em https://ggbm.at/wdQ5VRW9 (acesso 2 de maio de 2018)
} 
o quadrado da medida da hipotenusa é igual a soma dos quadrados das medidas dos catetos)? E para o registro simbólico $\left(\mathrm{a}^{2}=\mathrm{b}^{2}+\mathrm{c}^{2}\right)$ ? A partir da percepção da propriedade explicitada na manipulação das construções, o estudante teria condições de calcular a medida da hipotenusa de um triângulo retângulo cujos catetos medem $3 \mathrm{~cm}$ e $4 \mathrm{~cm}$ ?

O uso de softwares de Geometria Dinâmica pode contribuir para melhorar a compreensão da demonstração (e consequentemente, compreensão da propriedade), mas para isso é necessário criar condições. Isso será abordado no tópico seguinte.

\section{Demonstração Matemática Dinâmica}

O conceito proposto tem como fundamento teórico a Teoria dos Registros de Representações Semióticas de Duval. Uma recomendação primordial desse autor é "possibilitar a exploração de todas as variações possíveis de uma representação num registro fazendo prever, ou observar, as variações concomitantes de representação em outro registro" (Duval, 2009, p. 101). Retomando a reflexão feita anteriormente, entende-se que "concomitante" significa "ao mesmo tempo" ou "simultaneamente". A partir dessa consideração, entende-se que as demonstrações feitas em ambientes estáticos (papel ou quadro) podem dificultar a percepção das variações dos registros, porque tais ambientes não permitem variações concomitantes.

Para poder caracterizar as Demonstrações Matemáticas Dinâmicas, primeiramente é preciso deixar claro que se tratam de demonstrações que são expressas de forma escrita, mediante diferentes Registros de Representações Semióticas (linguístico, simbólico e visual). Trata-se do conceito de demonstração com o propósito de explicação. Não se trata de uma nova estratégia de demonstração, mas sim de como apresentá-la. A inovação está justamente na apresentação. Mais do que validar, o objetivo é criar condições para que o estudante possa compreender. Alguns poderiam pensar, intuitivamente, que as Demonstrações Matemáticas Dinâmicas são aquelas feitas no computador. De fato, tais Demonstrações precisam do computador para existirem e, mais especificamente, precisam dos softwares de GD. Todavia, nem toda demonstração matemática feita nesse ambiente é dinâmica.

Uma primeira característica da Demonstração Matemática Dinâmica está no fato de se integrarem dinamicamente, num mesmo ambiente, os diferentes registros de representações dos objetos da Matemática. Tal integração não pode ser feita de maneira desarticulada, ou seja, uma representação mais outra representação é igual a essa demonstração matemática. Até porque "Não é suficiente justapor representações de registros diferentes para que os 
alunos "vejam" as correspondências entre as unidades de sentido matematicamente pertinentes das diferentes representações justapostas" (Duval, 2011, p. 100). Numa demonstração dinâmica de uma propriedade ou teorema, as diferentes representações desse objeto aparecem concomitantemente e estão conectadas. Usam-se Registros Linguísticos, Simbólicos e Visuais Dinâmicos, além de Tratamentos e Conversões Dinâmicas. Por exemplo, na demonstração da propriedade do ângulo inscrito na circunferência as representações linguística, geométrica e algébrica estão conectadas de forma que quando se alteram as propriedades desse objeto, as diferentes representações também alteram e se adéquam às modificações, mantendo a coerência da demonstração. Uma contribuição dessa conexão é que o estudante pode perceber qual a relação que existe entre as diferentes representações, ou seja, quando se altera algo no registro algébrico o que acontece no registro geométrico.

Nas Demonstrações Matemáticas Dinâmicas, sempre que necessário e possível, os caracteres das representações que tratarem de um mesmo objeto terão as mesmas cores. Isso contribui para que os estudantes possam identificar e relacionar tais representações. Além disso, as propriedades necessárias para a compreensão da demonstração podem aparecer em espaços apropriados no ambiente ou em links.

Pode-se perceber que os principais requisitos para se obter uma Demonstração Matemática Dinâmica estão relacionados com o movimento e a integração concomitante das diferentes representações dos objetos da Matemática. Assim, para que se possam construir Demonstrações Matemáticas Dinâmicas é preciso ter um ambiente que permita a integração dinâmica das diferentes representações, tenha um editor intuitivo de texto e equações, além de espaços específicos para as diferentes representações. O GeoGebra e o GGBOOK (Nóbriga, 2015) são as plataformas que mais se adequam a essas condições.

\subsection{Um Exemplo De Demonstração Matemática Dinâmica Para Uma Propriedade Do Ângulo Inscrito Na Circunferência}

A seguir são apresentadas partes de uma folha de trabalho do livro "Aprendendo Geometria Plana com a Plataforma GeoGebra" (Nóbriga, 2017) em que são explorados os conceitos ângulo central, ângulo inscrito, ângulo do segmento circular e arco capaz. Primeiramente são apresentados dois applets para que, a partir da integração entre as diferentes representações, os estudantes possam compreender o que são os ângulos central e inscrito. Os applets estão representados nas figuras 9 e 10. 


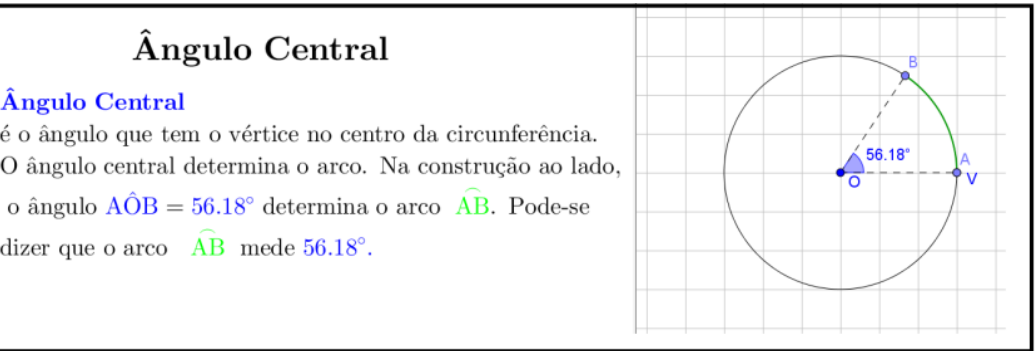

Figura 9-Ângulo central

(Disponível em https://ggbm.at/PybdQ59b acesso em 23 de abril de 2018)

\section{Ângulo Inscrito}

Ângulo Inscrito é o ângulo que tem o vértice na circunferência e os lados secantes a ela. O ângulo AĈ̉B é inscrito e mede $46.31^{\circ}$.

Figura 10-Ângulo Inscrito

(Disponível em https://ggbm.at/PybdQ59b acesso em 23 de abril de 2018)

Nas figuras 9 e 10 pode-se ver que os caracteres dos diferentes registros de representações dos objetos ângulos central e inscrito estão com as mesmas cores. Os estudantes podem arrastar os pontos $\mathrm{A}, \mathrm{B}$ ou $\mathrm{C}$ e observar as diferentes medidas desses ângulos. Quando se altera a medida representada no Registro Visual Dinâmico, a medida correspondente nos Registros Discursivos Dinâmicos também é alterada.

Em seguida, é apresentado um applet para que os estudantes possam manipular, fazer conjecturas e perceber uma importante propriedade do ângulo inscrito.

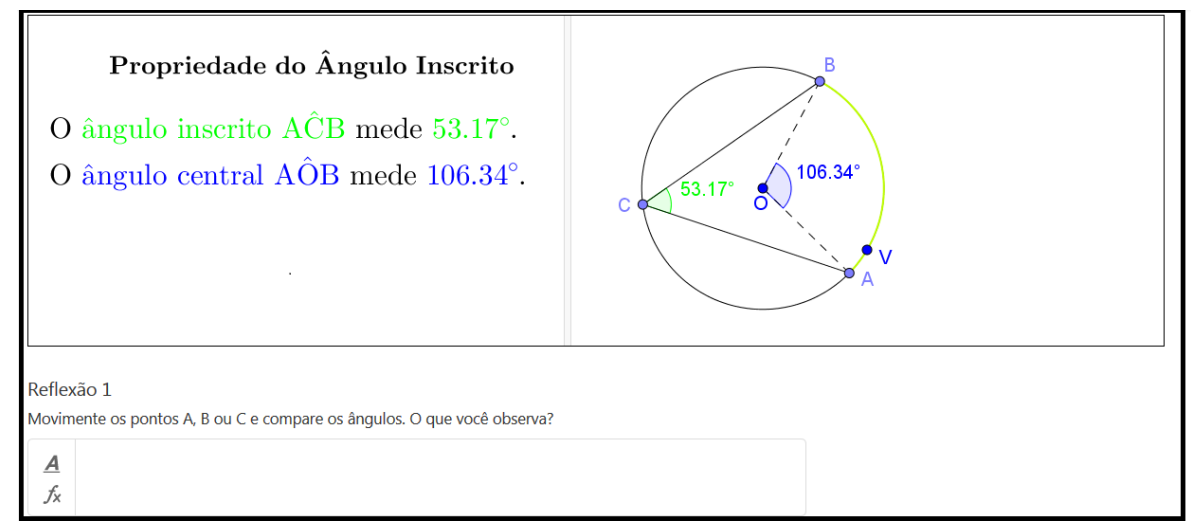

Figura 11-Construção para verificar propriedade do Ângulo Inscrito (Disponível em https://ggbm.at/PybdQ59b acesso em 23 de abril de 2018)

A construção da figura 11 apresenta orientações de manipulação na seção "Reflexão 1”. Os estudantes podem arrastar os pontos A, B ou C. Isso fará com que ocorram 
Tratamentos e Conversões Dinâmicas. O propósito é que ele possa observar e comparar as diferentes medidas dos ângulos central e inscrito. Nessa atividade, espera-se que o estudante perceba que a medida do ângulo inscrito é igual a metade da medida do ângulo central. Porém, pode acontecer do estudante perceber algo correto e que não reflete a propriedade desejada. Por exemplo, pode dizer que o ângulo central é sempre maior que o inscrito.

Gravina (2015, p.244) diz que:

na construção e na manipulação de figuras dinâmicas tem-se o germe do significado e da necessidade de uma demonstração. O procedimento de construção informa os 'fatos declarados'. As regularidades observadas mediante manipulação da figura dinâmica, informam sobre regularidades que não foram declaradas - os fatos implicitos - que se tornam passiveis de explicação via argumentação dedutiva. $\mathrm{O}$ entendimento da distinção entre fatos explícitos e implícitos é, sem dúvida, parte da gênese cognitiva do significado e da necessidade de uma demonstração.

Nesse sentido, após a atividade de exploração e elaboração de conjecturas, é apresentado o applet com a demonstração da propriedade. Diferentemente das demonstrações usuais apresentadas nos livros ou ambientes tradicionais, nas demonstrações dinâmicas as representações não são apresentadas todas de uma vez. De certa forma, o estudante controla a ordem de apresentação da demonstração por meio do seletor "etapas". A figura 12 mostra o applet da demonstração com o seletor na etapa 0 .

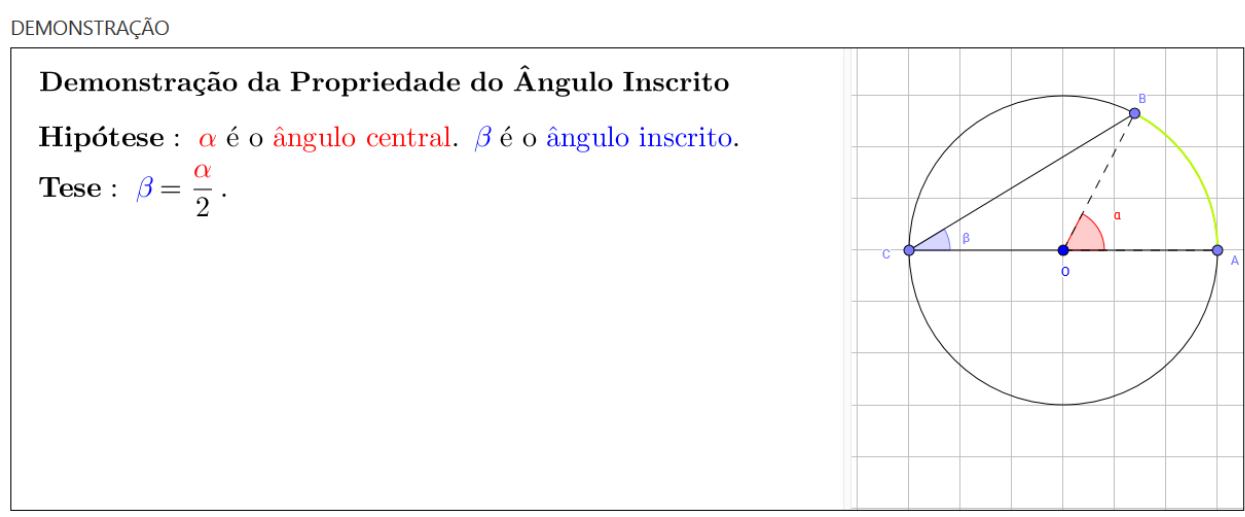

Figura 12-Etapa 0 da demonstração da propriedade do Ângulo inscrito em que o centro está num lado do ângulo

(Disponível em https://ggbm.at/PybdQ59b acesso em 23 de abril de 2018)

O applet representado na figura 12 apresenta o caso mais simples em que o centro está num lado do ângulo. Ao movimentar o seletor "etapas" para a direita, o estudante poderá ver as imagens que estão nas figuras 13 e 14. 


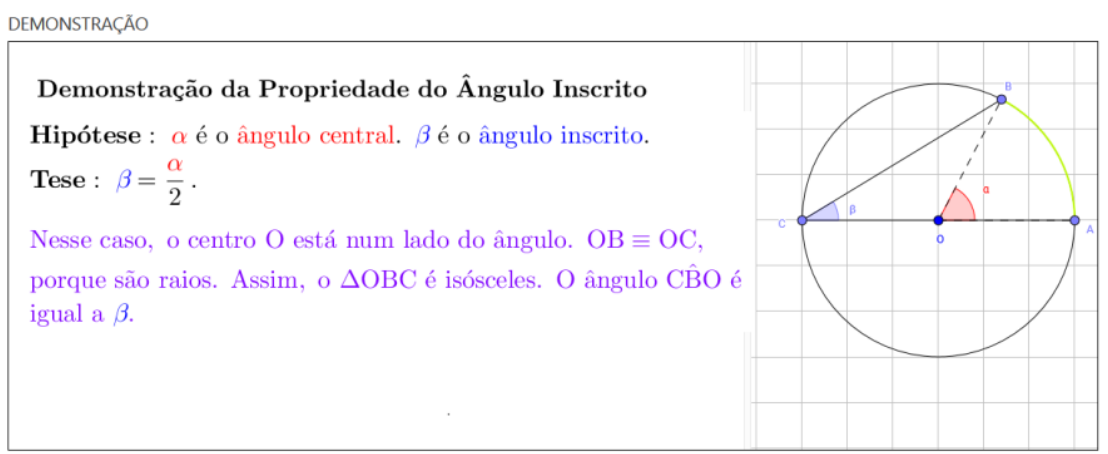

Figura 13-Etapa 1 da demonstração da propriedade do Ângulo inscrito em que o centro está num lado do ângulo

(Disponível em https://ggbm.at/PybdQ59b acesso em 23 de abril de 2018)

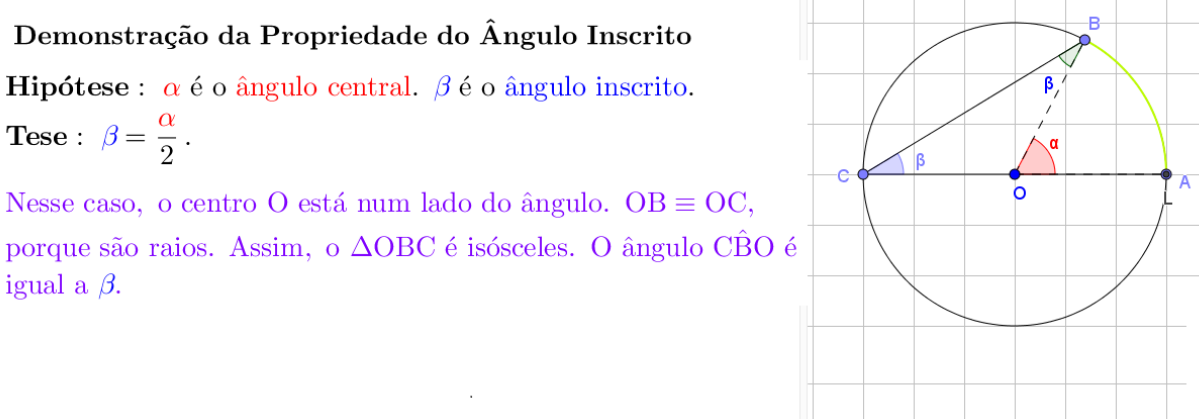

Figura 14-Etapa 2 da demonstração da propriedade do Ângulo inscrito em que o centro está num lado do ângulo

(Disponível em https://ggbm.at/PybdQ59b acesso em 23 de abril de 2018)

É preciso observar que a única diferença nas imagens das figuras 13 e 14 é a marca do ângulo $\beta$ no vértice $B$. Isso era importante para que a propriedade do ângulo externo ficasse mais visível na etapa seguinte. Na etapa 3 (figura 15) as diferentes representações do objeto "ângulo externo" estão com mesma cor. A propriedade do ângulo externo era essencial para a compreensão da demonstração. Todavia, poderia acontecer do estudante não se lembrar de tal propriedade. Assim, nas orientações contidas na construção (figura 16) há um link para a folha de trabalho que abordou essa propriedade.

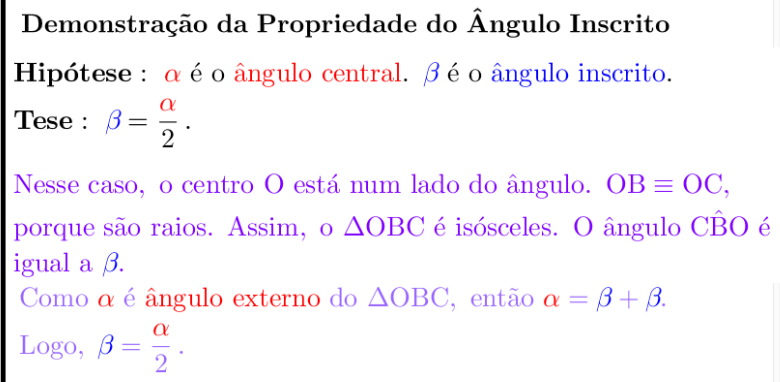

Figura 15-Etapa 3 da demonstração da propriedade do Ângulo inscrito em que o centro está num lado do ângulo

(Disponível em https://ggbm.at/PybdQ59b acesso em 23 de abril de 2018) 
Orientações para a visualização da demonstração

Altere o seletor "etapas" e observe as etapas da demonstração. Compreendeu bem?

Caso não tenha entendido a propriedade do ângulo externo clique aqui e revise.

Volte o seletor para a etapa 0 . Movimente o ponto C para baixo. Observe as etapas da demonstração.

Compreendeu bem?

Volte o seletor para a etapa 0. Movimente o ponto C para cima. Observe as etapas da demonstração.

Compreendeu bem?

$\underline{A}$

$f_{x}$

Figura 16-Orientações para visualização da demonstração

(Disponível em https://ggbm.at/PybdQ59b acesso em 23 de abril de 2018)

$\mathrm{Na}$ etapa 3, a demonstração é concluída para esse caso. Mas se o ângulo central estiver no interior ou no exterior do ângulo inscrito a demonstração não é a mesma. Nas figuras 17 e 18 é possível ver as demonstrações para esses casos.

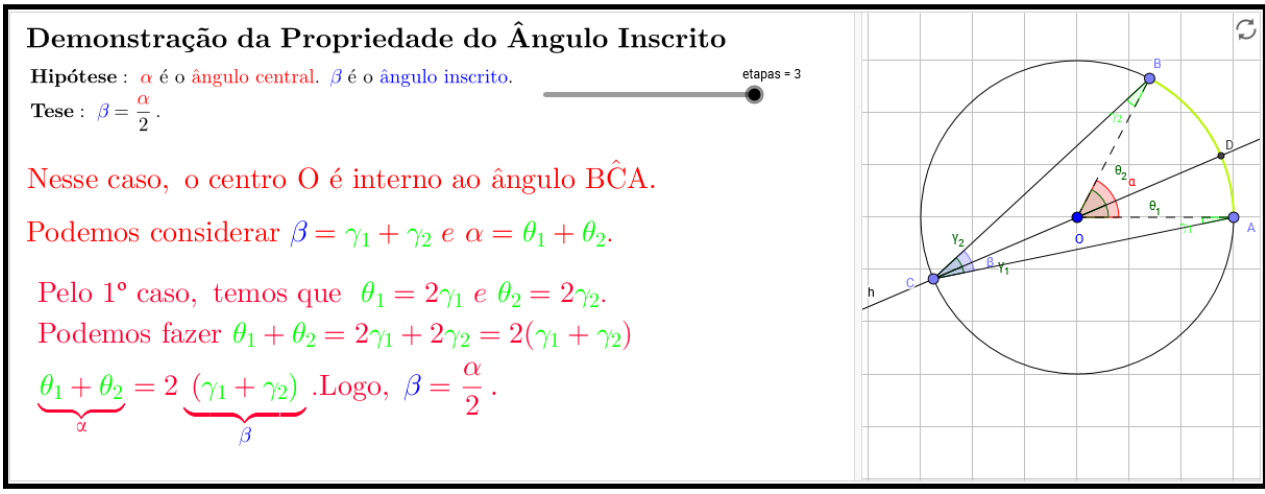

Figura 17-Demonstração da propriedade do Ângulo inscrito com ângulo central no interior do ângulo inscrito

(disponível em https://ggbm.at/PybdQ59b acesso em 23 de abril de 2018)
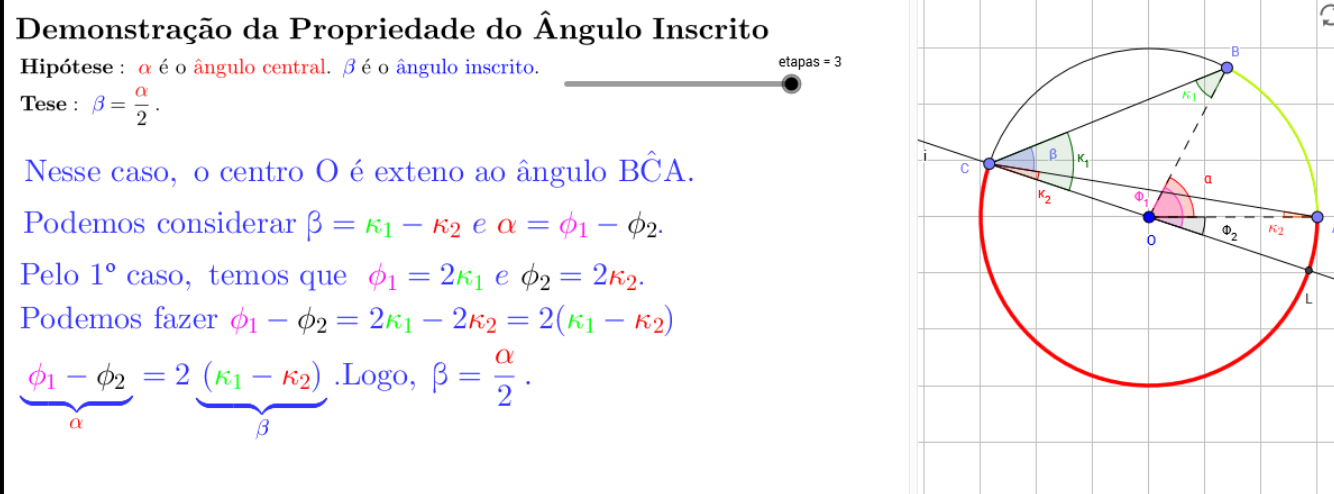

Figura 18-Demonstração da propriedade do Ângulo inscrito com ângulo central no exterior do ângulo inscrito

(disponível em https://ggbm.at/PybdQ59b acesso em 23 de abril de 2018)

O Registro Discursivo das demonstrações se ajustam automaticamente quando o ponto 
C é movimentado e altera o caso. As demonstrações feitas para os casos em que o ângulo central está no interior ou no exterior do ângulo inscrito dependem do $1^{\circ}$ caso. Assim, o applet foi projetado para mostrar, primeiramente, o caso em que o centro está sobre um dos lados do ângulo inscrito. É importante que o professor fique atento a isso e oriente a manipulação da demonstração.

\section{Considerações Finais}

Este artigo trás alguns conceitos novos para a Teoria de Registros de Representações Semióticas: Registro Figural Dinâmico, Registro Linguístico Dinâmico, Registro Simbólico Dinâmico, Registro Discursivo Dinâmico, Tratamento Dinâmico e Conversão Dinâmica. A formalização de tais conceitos era necessária, porque as características dos registros e das transformações em ambientes de Geometria Dinâmica são diferentes das produzidas em ambientes estáticos. Além disso, tais conceitos eram necessários também para a formalização do conceito proposto: Demonstrações Matemáticas Dinâmicas.

Foi apresentado um exemplo de Demonstração Matemática Dinâmica, mas muitos outros podem ser vistos em Nóbriga (2017). As novas possibilidades da plataforma GeoGebra permitem a criação de livros digitais dinâmicos. Mas esses não podem ser simples reproduções dos livros estáticos em ambientes dinâmicos. Assim, é necessário pensar sobre como devem ser feitos os materiais nesse ambiente. A Demonstração Matemática Dinâmica é um exemplo de como as demonstrações matemáticas podem ser apresentadas nessa plataforma.

Alguns experimentos utilizando a Demonstração Matemática Dinâmica foram feitos, na disciplina de Geometria 1, com estudantes do $1^{\mathrm{o}}$ semestre de um curso de licenciatura em Matemática. No entanto, ainda não foram feitas análises formais sobre os efeitos desse tipo de demonstração no processo de aprendizagem e ensino de Matemática. É evidente que muitas outras experimentações precisam ser feitas, mas essas primeiras utilizações apresentaram resultados satisfatórios quanto às possibilidades de contribuições. Para que tais contribuições possam ser ainda mais efetivas na sala de aula é preciso preparar professores e autores para a utilização e produção de livros didáticos com demonstrações dinâmicas.

\section{Referências}

Bellemain, F. (2001). Geometria Dinâmica: diferentes implementações, papel da manipulação direta e usos na aprendizagem. In International Conference on Graphics Engineering for Arts and Design (pp. 1314-1329). São Paulo: USP. 
Bellemain, F, \& Correia, E.M. (2004). Geometria Dinâmica: fundamentos epistemológicos. EGraFIA 2004.

Bicudo, I. (2002). Demonstração em Matemática. BOLEMA: Boletim de Educação Matemática, 18, 79-90.

Dolce, O., \& Pompeu, J. N. (2013). Fundamentos de Matemática Elementar (Geometria plana). São Paulo: Editora Atual. Volume 9.

Duval, R. (2009). Semiósis e Pensamento Humano: Registros semióticos e aprendizagens intelectuais. (L. F. LEVY \& M. R. . SILVEIRA, Trans.) (1st ed.). São Paulo: Livraria da Física.

Duval, R. (2011). Ver e Ensinar a Matemática de outra forma. Entrar no modo matemático de pensar: os registros de representações semióticas. (T. M. M. CAMPOS, Ed.) (Vol. 1). São Paulo: PROEM.

Gravina, M. A. (2015). O Potencial Semiótico Do Geogebra Na Aprendizagem Da Geometria: Uma Experiência Ilustrativa. Vidya, 35(2), 18. Recuperado de http://periodicos.unifra.br/index.php/VIDYA/article/view/605

Hanna, G. (1990). Some pedagogical aspects of proof. Interchange, 21(1), 6-13. https://doi.org/10.1007/BF01809605

Isotani, S., \& Brandão, L. de O. (2006). Como Usar a Geometria Dinâmica? O Papel do Professor e do Aluno Frente às Novas Tecnologias. In Anais do Workshop de Informática na Escola (Vol. 1).

Lourenço, \& M. L. (2002). A Demonstração com Informática Aplicada à Educação 1. BOLEMA: Boletim de Educação Matemática, 15.

Nóbriga, J. C. C. (2015). GGBOOK: uma plataforma que integra o software de geometria dinâmica geogebra com editor de texto e equações a fim de permitir a construção de narrativas matemáticas dinâmicas. (Tese de doutorado em Educação). Universidade de Brasília, Brasília.

Nóbriga, J. C. C. (2017). Aprendendo Geometria Plana com a Plataforma GeoGebra. Blumenau: Livre (< https://www.geogebra.org/m/hsXHDRX7\#material/gKNVfTXE $>$ ).

Preiner, J. (2008). Introducing dynamic mathematics software to mathematics teachers: The case of GeoGebra (Dissertação de mestrado em Educação Matemática). University of Salzburg, Salzburg.

Salazar, V. J. F. (2011). Desenvolvimento de esquemas de utilização na interação com Geometria Dinâmica, Unión: Revista Iberoamericana de Educación Matemática. 3. p. $169-178$

Salazar, J. V. F., \& Almouloud, S. A. (2015). Registro figural no ambiente de geometria dinâmica. Educ. Matem. Pesq, 17(5), 919-941. 
Submetido em: 25/02/2019

Aceito em: 15/04/2019 